\title{
Unusual prevertebral collection presenting as an obstructive laryngopharyngeal swelling
}

\author{
Fergus Cooper 두 , Lyris Onwordi, Bhaskar Ram, Vamsidhar Vallamkondu
}

Department of Otolaryngology and Head \& Neck Surgery, Aberdeen Royal Infirmary, Aberdeen, UK

\section{Correspondence to Fergus Cooper; \\ fergus.cooper2@nhs.scot}

Accepted 8 November 2020

\section{DESCRIPTION}

A 34-year-old man was referred to the otolaryngology department via the acute medical assessment ward with progressive dysphagia over a period of months with new onset dyspnoea and odynophagia. The patient was unable to swallow on admission and had mild dyspnoea and voice muffling, but no stridor and was maintaining oxygen saturations above $96 \%$ on room air. $\mathrm{He}$ showed no signs of infection and was systemically well. Flexible nasolaryngoscopy revealed a large smooth globular swelling in the midline of the posterior laryngopharynx (figure 1, video 1 ). The overlying mucosa appeared normal. The swelling obscured the posterior half of the glottis, hence the patient's mild dyspnoea. The patient was administered intravenous dexamethasone

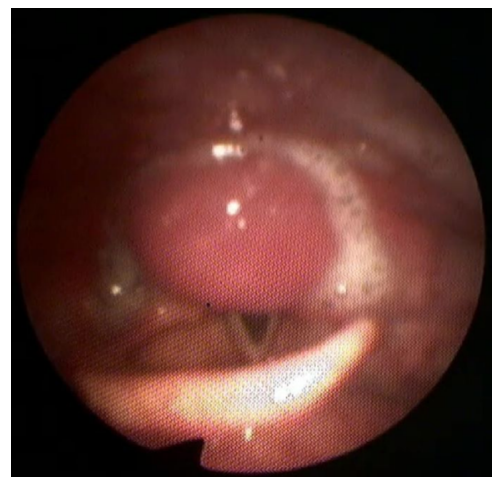

Figure 1 Flexible nasolaryngoscopy showing a midline swelling of the posterior pharyngeal wall with pooling of saliva and occlusion of the posterior aspect of the larynx.

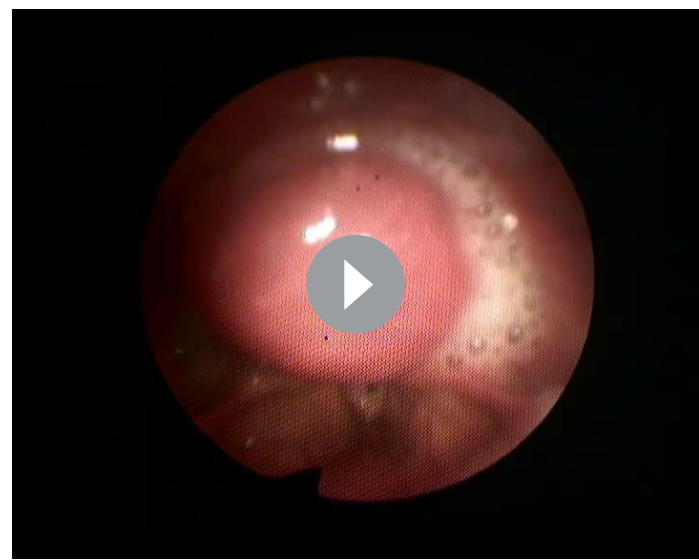

Video 1 Flexible nasolaryngoscopy revealing a large smooth globular swelling in the midline of the posterior laryngopharynx obscuring the posterior aspect of the larynx.

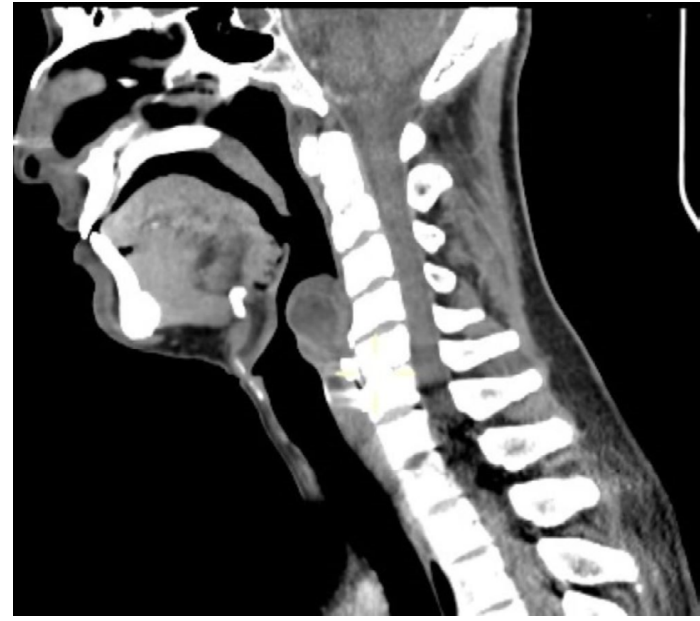

Figure 2 Sagittal view of CT of the neck showing prevertebral cystic swelling at the level of C3 and C4.

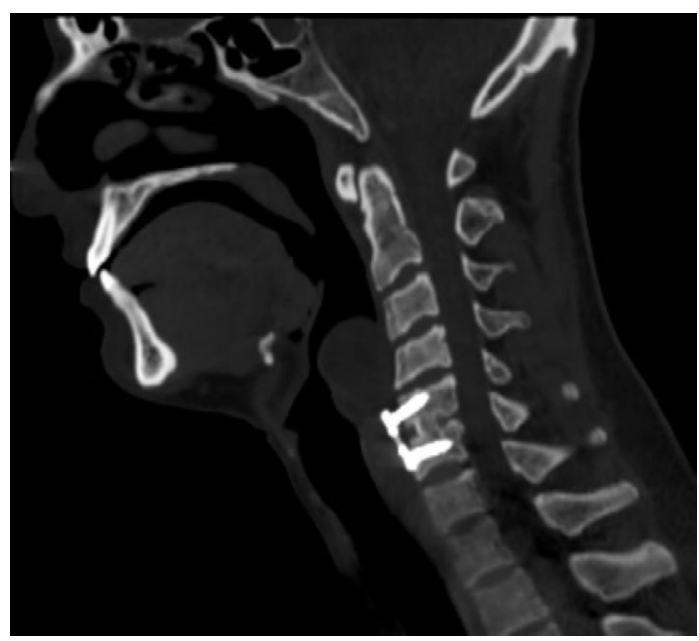

Figure 3 Sagittal view of CT of the neck with altered windowing to show metal prosthesis at $\mathrm{C} 5$ and $\mathrm{C} 6$.

to provide some symptomatic relief prior to arranging a CT scan of his neck with contrast. The CT scan showed a well-defined fluid-filled collection with thick walls in the prevertebral space at the level of C3 and C4, compressing the retropharyngeal space and bulging into the laryngopharynx (figures 2-5). The collection appeared to be arising from the upper screw of metal prosthesis used for cervical spine stabilisation. This was revisited with the patient who actually described having $\mathrm{C} 5 / 6$ anterior cervical discectomy and fusion for a traumatic cervical spine injury overseas around 10 years ago. 


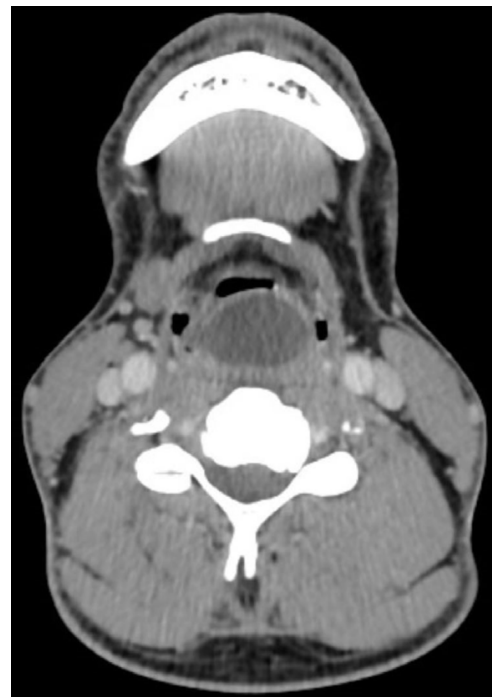

Figure 4 Axial view of $\mathrm{CT}$ of the neck showing compression on laryngopharynx.

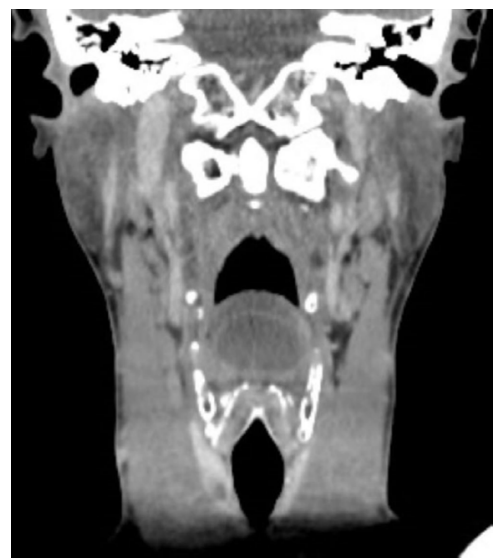

Figure 5 Coronal view of $\mathrm{CT}$ of the neck showing midline cystic swelling into the laryngopharynx.

These findings were discussed with the neurosurgery team, and potential diagnoses and management options were considered. It was felt that the swelling was likely to represent a reactionary cyst and unlikely to represent a meningocele $e^{1}$ or spinal tuberculosis, ${ }^{2}$ so drainage and biopsy via direct laryngoscopy

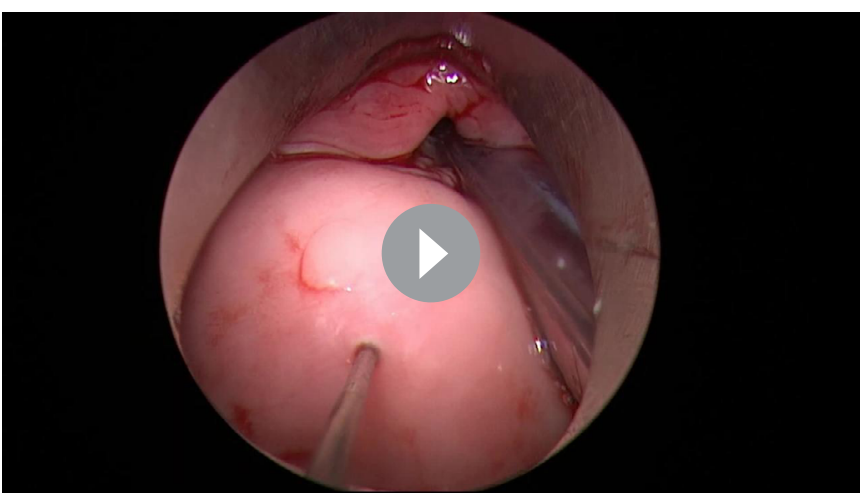

Video 2 Endoscopic-assisted aspiration of cyst via direct laryngoscopy.

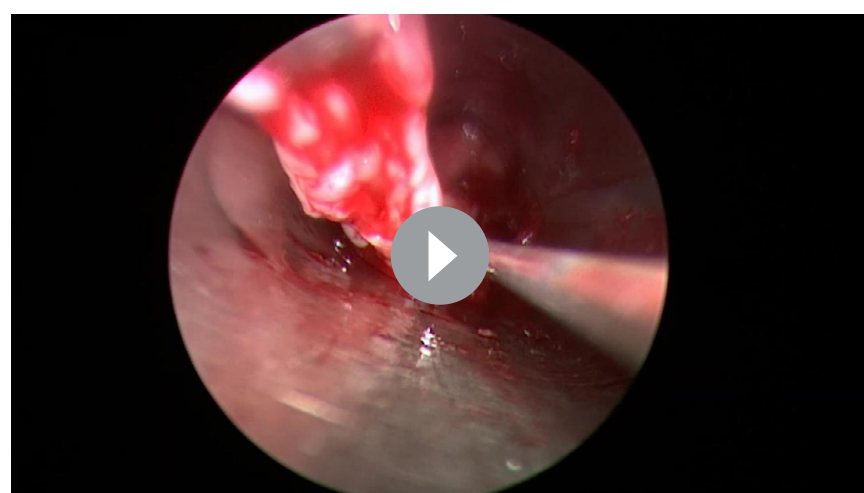

Video 3 Endoscopic-assisted deroofing of cyst via direct laryngoscopy.

was felt to be a safe strategy to relieve the patient's symptoms and obtain samples for microbiology and histology.

The patient was taken to theatre and, under general anaesthetic, the swelling was aspirated and deroofed via direct laryngoscopy and endoscopic assistance (videos 2 and 3). Care was taken not to breach the posterior wall of the cavity to avoid paravertebral structures.

Samples of fluid were sent for culture and sensitivity and beta- 2 transferrin analysis. The tissue from the deroofing was sent for histological analysis.

A nasogastric tube was inserted for postoperative feeding and the patient was kept nil by mouth for 48 hours. A 5 -day course of prophylactic co-amoxiclav was commenced. The patient's airway symptoms were relieved immediately postoperatively. One day after the nasogastric tube was removed, the patient was able to tolerate a normal diet and there were no signs of infection. Repeat flexible nasolaryngoscopy showed the swelling had shrunk significantly, with just a small lip of redundant mucosal tissue visible at the post-cricoid region (video 4). The patient was discharged and followed-up via telephone consultation. The histology results revealed inflamed benign squamous epithelium and granulation tissue in keeping with cyst deroofing. The patient will be reviewed in the otolaryngology clinic to check for recurrence. If the swelling recurs, his case will be discussed with the spinal surgery team to consider removal of the spinal prosthesis.

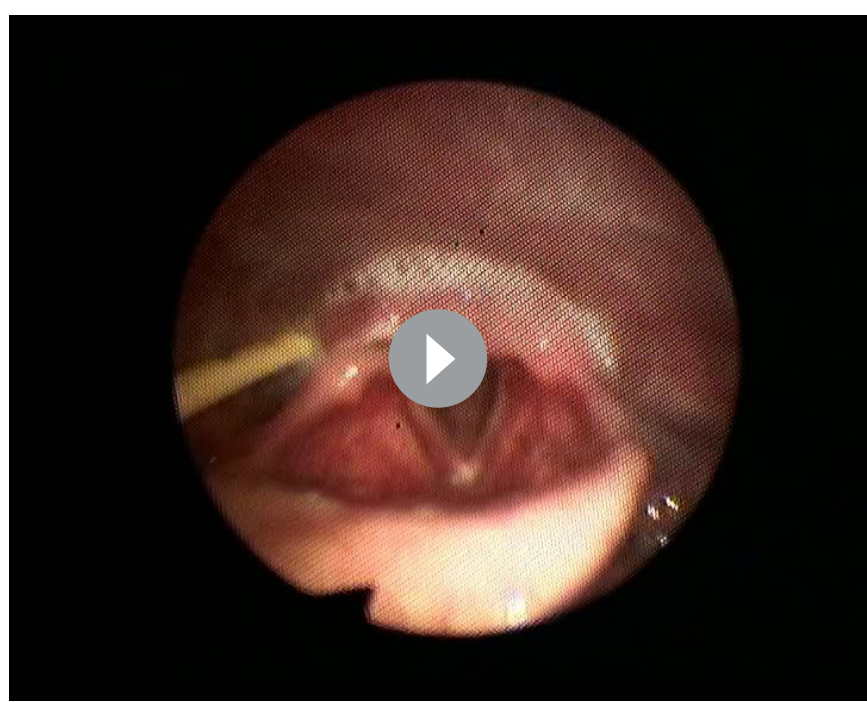

Video 4 Improved appearance of laryngopharynx on repeat flexible nasolaryngoscopy 3 days postoperatively. 
Learning points

- Obtaining a thorough medical history including details of any previous surgery can be particularly useful in cases of diagnostic uncertainty.

- Deroofing of this prevertebral swelling via a laryngoscopic approach proved to be a safe and relatively minimally invasive management option.

- Flexible nasolaryngoscopy remains a key part of examination in the assessment and evaluation of any patient with airway compromise and odynophagia.

Contributors All four authors contributed to the drafting of this case report as well as assisting with data collection and editing. More specifically, I, Fergus Cooper, am the lead author of this case report and collected the relevant media associated with the case. I was also heavily involved in this patient's care as an inpatient and recorded his postoperative flexible laryngoscopy. LO assisted with editing the manuscript and obtaining data by examining the patient. The preoperative flexible laryngoscopy is performed by LO. VV and BR were the lead consultants involved in this patient's care and primary operating surgeons for the deroofing procedure. VV supervised me in writing the manuscript. BR assisted with data collection and safely extracting media from clinical recording devices. All four authors have read and approved the final manuscript. We agree to be accountable for all aspects of the work and will ensure that any questions related to the accuracy or integrity of any part of the work are appropriately investigated and resolved.

Funding The authors have not declared a specific grant for this research from any funding agency in the public, commercial or not-for-profit sectors.

Competing interests None declared.

Patient consent for publication Obtained.

Provenance and peer review Not commissioned; externally peer reviewed.

\section{ORCID iDs}

Fergus Cooper http://orcid.org/0000-0002-1911-0440

Vamsidhar Vallamkondu http://orcid.org/0000-0001-9221-0651

\section{REFERENCES}

1 Kos MP, Peederman SM, David EF, et al. Dysphagia caused by retropharyngeal masses originating from the cervical spine. Otolaryngol Head Neck Surg 2009;140:612-3.

2 Christoforidou A, Metallidis S, Kollaras P, et al. Tuberculous retropharyngeal abscess as a cause of oropharyngeal dysphagia. Am J Otolaryngol 2012;33:272-4.

Copyright 2020 BMJ Publishing Group. All rights reserved. For permission to reuse any of this content visit

https://www.bmj.com/company/products-services/rights-and-licensing/permissions/

BMJ Case Report Fellows may re-use this article for personal use and teaching without any further permission.

Become a Fellow of BMJ Case Reports today and you can:

- Submit as many cases as you like

- Enjoy fast sympathetic peer review and rapid publication of accepted articles

- Access all the published articles

- Re-use any of the published material for personal use and teaching without further permission

Customer Service

If you have any further queries about your subscription, please contact our customer services team on +44 (0) 2071111105 or via email at support@bmj.com.

Visit casereports.bmj.com for more articles like this and to become a Fellow 